\title{
Net Photosynthesis and Growth of Three Novel Woody Species Under Water Stress: Calycanthus occidentalis, Fraxinus anomala, and Pinckneya pubens
}

\author{
J. Ryan Stewart ${ }^{1}$ \\ Department of Natural Resources and Environmental Sciences, University \\ of Illinois at Urbana-Champaign, 1011 PSL MC-634, 1201 South Dorner \\ Drive, Urbana, IL, 61801
}

Reid D. Landes

Department of Biostatistics, University of Arkansas for Medical Sciences, Little Rock, AR 72205-7199

Andrew K. Koeser and Andrea L. Pettay

Department of Natural Resources and Environmental Sciences, University of Illinois at Urbana-Champaign, Urbana, IL, 61801

Additional index words. western sweetshrub, single-leaf ash, fevertree, photosynthesis, drought, flooding

\begin{abstract}
Frequent episodes of water stress in managed landscapes have led the nursery industry to look for attractive woody species that perform well under extreme conditions of drought and flooding. We chose to evaluate three taxa with highly localized natural distributions in the United States, Calycanthus occidentalis (north-central California), Fraxinus anomala (northeastern Utah), and Pinckneya pubens (northeastern Florida), each of which may merit further use under cultivated conditions beyond their respective ranges. Although widespread cultivation of each taxon may not be possible as a result of limitations related to cold hardiness, we hypothesized that each species can tolerate extremes in soil moisture availability more so than their native habitats imply. Our objective was to characterize, under greenhouse conditions, how the quantity of soil water affects gas exchange of potted plants of each species. Plants were divided into five groups, each exposed to treatment conditions ranging from complete submersion to severe drought. Complete submersion killed plants of $C$. occidentalis and $F$. anomala, although in drought or severe drought conditions, $C$. occidentalis plants had lower net photosynthesis and less leaf area and plant dry weight than control plants. Net photosynthesis, leaf area, and plant dry weight of partially flooded plants, however, were not found to be significantly less than that of the control plants. Mean net photosynthetic levels and plant dry weights of severe drought, drought, and control $F$. anomala did not differ. While severe drought plants of $P$. pubens exhibited much lower levels of net photosynthesis, but not plant dry weights or leaf area, than the control plants, those exposed to drought, partial flood, and complete submersion were not found to differ in net photosynthesis levels from the control plants. Due to the sustained tolerance of $F$. anomala and $P$. pubens to a range of extreme soil moisture conditions, as exhibited by net photosynthetic responses, carbon accumulation, and survival, we conclude that use of these species in landscapes is warranted if invasiveness and other potential problems are not identified. Calycanthus occidentalis, however, appears unsuitable for cultivation in areas with organic soils greater than $\approx 66 \%$ and lower than $\approx 30 \%$ soil moisture content as a result of its high mortality in flooded conditions and poor physiological responses under dry conditions.
\end{abstract}

Environmental stresses such as extremes in soil water availability prevent many attractive woody plants from surviving in managed landscapes (Kjelgren et al., 2000). As such,

Received for publication 14 Mar. 2007. Accepted for publication 21 May 2007.

${ }^{1}$ To whom reprint requests should be addressed; e-mail rstewart@uiuc.edu. there is an increasing demand in the nursery industry for aesthetic, yet stress-resistant, trees and shrubs. Because of the high costs of propagation, cultivation, transplantation, and establishment, trees and shrubs constitute a substantial financial investment by nurseries (Campbell et al., 2001; Harris et al., 1999). Efforts to ensure plant survival, and thus to minimize economic losses, are readily welcomed by the nursery industry.
It is generally assumed that a species' native habitat and climate are reliable indicators of the prospective cultivated range of a species. Past research, however, has shown that some novel ornamental woody species have the ability to withstand stresses not normally experienced in their native ranges (Schrader et al., 2005; Stewart and Graves, 2004).

We decided to evaluate the relative vigor, as indicated by net photosynthesis and plant growth, of three taxa that grow wild in relatively small areas in the United States and may merit use in managed landscapes: Calycanthus occidentalis Hook. \& Arn. (western sweetshrub), Fraxinus anomala Torr. ex S. Watson (single-leaf ash), and Pinckneya pubens Michx (fevertree). Calycanthus occidentalis, a western congener of the widely cultivated Calycanthus floridus L., is a multistemmed shrub or small tree native to primarily the Sierra Nevada in north-central California, but also is found in Oregon and Washington (Hickman, 1993). It is a common shrub of moist habitats, including stream borders and shaded canyons (Grant, 1950; Hickman, 1993; Shevock et al., 1992). Similar to C. occidentalis, F. anomala is a multistemmed shrub or small tree but is found along rimrock or drainages in pinyonjuniper forests within Arizona, California, Colorado, New Mexico, Nevada, and Utah (Welsh, 1987). Unlike many of its congeners, $F$. anomala generally has monofoliate leaves, but frequently has trifoliate leaves as well (J. R. Stewart, personal observation). Pinckneya pubens is also a multistemmed shrub or small tree with large distinctive flowers that is found in Georgia, northern Florida, and South Carolina (Delprete, 1996). The taxon grows in swamp forests, edges of boggy areas, and other poorly drained soils (Delprete, 1996). Because marshy areas are drained for agriculture and urban development, $P$. pubens is losing its natural habitat (J. Sharma, personal communication). The respective semiarid and marshy habitats of $F$. anomala and $P$. pubens imply that both species may be tolerant of at least some extremes in soil moisture found in horticultural landscapes.

Our objective was to characterize, under greenhouse conditions, the effect of soil water availability on leaf gas exchange and carbon-allocation patterns in potted plants of each species. Measuring these physiological variables has been shown to be an effective method of gauging the potential landscape performance of woody species (Balok and St. Hilaire, 2002; Bsoul et al., 2006; Schrader et al., 2005; Stewart and Graves, 2004).

\section{Materials and Methods}

Fifty 3-month-old C. occidentalis plants, indigenous to Kings Canyon National Park, $\mathrm{CA}$, were propagated from seed and grown in a greenhouse. The plants were grown in 2.8-L pots (height $=18.4 \mathrm{~cm}$, top diameter $=16.2$ $\mathrm{cm})$. Seventeen 4-year-old, seed-propagated $F$. anomala plants indigenous to Dinosaur 
National Monument, UT, and 30 9-monthold, vegetative-cutting-propagated $P$. pubens plants indigenous to Liberty County, FL, were grown in 14.6-L (height $=27.9 \mathrm{~cm}$, top diameter $=30.2 \mathrm{~cm}$ ) and 3.64-L (height $=$ $15.9 \mathrm{~cm}$, top diameter $=20.3 \mathrm{~cm}$ ) pots, respectively. Containers of plants of each species were filled with soilless media (LC1 Sunshine Mix; Sun Gro Horticulture, Bellevue, WA) and were then inserted into larger pots [volume $=3 \mathrm{~L}$, height $=15.2 \mathrm{~cm}$, top diameter $=20.3 \mathrm{~cm}$ (C. occidentalis and $P$. pubens); volume $=22 \mathrm{~L}$, height $=29.2 \mathrm{~cm}$, top diameter $=35.6 \mathrm{~cm}(F$. anomala $)] \mathrm{cov}-$ ered with aluminum foil to minimize solar heat load of the rhizosphere of each plant.

There were five treatments: severe drought, moderate drought, moist (i.e., control), partial flood, and flood. These treatments represented the range of water stress levels that ornamental plants are commonly exposed to in managed landscapes. The moist treatment was considered the control as a result of conventional nursery practices both in the greenhouse and in the field to maintain a moist rhizosphere for optimal plant growth. Potted plants were irrigated to the waterholding capacity of drained root zones every 12,8 , and $4 \mathrm{~d}$ for plants in the severe drought, moderate drought, and moist treatments, respectively. The lower half of the aluminum foil-covered containers in the partial flood treatment was continuously saturated with a column of tap water. Entire root zones of the flooded plants were completely submerged by maintaining the water column in the pots at the surface of the medium. Within each species, assignment of treatment and greenhouse position of plants were completely random. The three species were separated spatially to facilitate intraspecific comparisons. Sample sizes per treatment were equal within $C$. occidentalis $(\mathrm{n}=10)$ and $P$. pubens $(\mathrm{n}=6)$. In F. anomala, severe drought and drought had four and the remaining treatments three. Treatments were imposed on 19 June and ended on 30 Aug. 2006.

When the plants in the severe drought, drought, and moist treatments were scheduled for irrigation on the same date (13 July and 6 Aug.), all plants were fertilized with 8.92 mm N (20N-20P-20K) (Plant Products, Brampton, ON, Canada) in tap water. Root zones of plants in the partial flood and flood treatments were fertilized after removing them from the foil-covered pots. Multiple $1000-\mathrm{W}$, high-pressure sodium lamps provided supplemental irradiance between 0600 and $2200 \mathrm{HR}$. Mean air temperature $\left(27.7^{\circ} \mathrm{C}\right)$ was determined with a datalogger (CR23X; Campbell Scientific, Logan, UT), which also logged irradiance data with a probe (QSOELEC; Apogee Instruments, Logan, UT) to determine mean photosynthetically active radiation $\left[211 \mu \mathrm{mol} \cdot \mathrm{m}^{-2} \cdot \mathrm{s}^{-1}\right.$ (daily maximum $=$ $\left.\left.495 \mu \mathrm{mol} \cdot \mathrm{m}^{-2} \cdot \mathrm{s}^{-1}\right)\right]$.

Net photosynthesis of the youngest, fully expanded leaf on the longest stem of each plant was measured during the middle of the day with a steady-state photosynthesis system (LI-6400; LI-COR, Lincoln, NE) with an LED light source (model 6400-02B; LICOR) set at $1500 \mu \mathrm{mol} \cdot \mathrm{m}^{-2} \cdot \mathrm{s}^{-1}$, which is above the light saturation point of several deciduous woody species (Dougherty et al., 1979; Landhäusser and Lieffers, 2001; McCarron and Knapp, 2001), before irrigating on 13 July, 6 Aug., and 30 Aug. Ambient $\mathrm{CO}_{2}$ concentration in the cuvette was set at $400 \mu \mathrm{mol} \mathrm{CO} \mathrm{CO}^{-1}$. Soil moisture content by volume of the upper $6 \mathrm{~cm}$ of the root zones was determined on each date before irrigation with a Thetaprobe (model ML2x; Delta-T Devices, Cambridge, UK), which was set at the factory-calibrated organic soil type option. Medium redox potential of each plant in the partial flood and flooded treatments was also measured at a soil depth of $10.7 \mathrm{~cm}$ with a platinum combination electrode $(\mathrm{Ag}+/$ $\mathrm{AgCl}$, Accumet; Fisher Scientific, Hampton, $\mathrm{NH})$ before measurement of net photosynthesis. At treatment termination, leaf area was measured with a leaf area meter (LI3000; LI-COR) and roots, stems, and leaves of each plant were oven-dried at $65^{\circ} \mathrm{C}$ for $3 \mathrm{~d}$ before determining dry weights of each.

Net photosynthesis of each species was analyzed with a two-factor, repeated-measures analysis of variance (ANOVA) to evaluate the effects of treatment, measurement date, and their interaction within a species. When evidence of an interaction was present, effects of the treatments at each measurement date (i.e., simple effects) were considered; otherwise, comparisons of plants in each treatment across time (i.e., main effects) were conducted. Significant interaction effects were partitioned into three tests: partial flood, control, and drought treatments by measurement date [4 degrees of freedom (df)]; flood and control treatments by measurement date ( $2 \mathrm{df}$ ); and severe drought and control treatments by measurement date ( $2 \mathrm{df})$. The goal of the study was to see how water stress treatments affected the plants compared with a presumably nonstressed, control treatment. Therefore, for each species, each stress treatment was compared individually with the control treatment rather than conducting multiple comparisons among all five treatments. When significant interactions necessitated comparisons among the treatments at each of the three measurement dates (i.e., comparisons of simple effects), the significance level was divided by three, which is a Bonferroni-type correction (Westfall et al., 1999), for each set of comparisons within a measurement date.

Mean dry weights of roots, stems, leaves, and whole plants were compared among the treatments within each species. Overall comparisons were made with a one-factor ANOVA and pairwise comparisons of the control plants to plants in each of the other treatments were made with $t$ tests and corrected with Dunnett's method for multiple comparisons (Westfall et al., 1999). A significance level of $P \leq 0.05$ was used for all statistical tests. For all estimates provided, we also provide the relevant $95 \%$ confidence intervals. Values of test statistics are presented for reported $P$ values having no accompanying estimate; subscripts on $F$ statistics are the numerator df (ndf) and denominator df (ddf), respectively (e.g., $F_{n d f, d d f}$ ). Subscripts on $t$ statistics are the df (e.g., $\left.t_{d f}\right)$. All analyses were conducted using the MIXED procedure in SAS/STAT version 9.1 (SAS, Cary, NC).

No prior estimates of within-species variability in photosynthesis were available when this experiment was conducted. To estimate within-species variability, one-factor ANOVAs were performed for each species when photosynthesis was measured after treatment initiation on 29 June 2006 . Resulting mean square errors from the ANOVAs were considered measures of within-species variability. These measures were then used to calculate effect sizes detectable with $80 \%$ power on a $5 \%$ level test of no mean differences among treatments. The effect size was the ratio of the standard deviation of treatment means to the standard deviation of photosynthesis among plants within species. The detectable effect sizes were estimated to be $0.5149,1.018$, and 0.7076 of $C$. occidentalis, $F$. anomala, and $P$. pubens, respectively.

\section{Results}

Calycanthus occidentalis. Averaged over time, mean net photosynthesis of $C$. occidentalis plants in the drought treatment was $3.40 \mu \mathrm{mol} \cdot \mathrm{m}^{-2} \cdot \mathrm{s}^{-1}[95 \%$ confidence interval (CI): 2.07 to 4.72 ] less than that of plants in the control treatment $(P<0.0001)$ (Table 1). No differences in net photosynthetic rate were found, however, between the control and partially flooded treatments $(1.03 \mu \mathrm{mol}$. $\mathrm{m}^{-2} \cdot \mathrm{s}^{-1}, 95 \% \mathrm{CI}: 2.36$ to $\left.-0.29 ; P=0.12\right)$ (Table 1).

Due to an interaction between treatment and time, comparisons between plants in the control and flood treatments $\left(F_{2,90}=10.54\right.$; $P<0.0001)$ and control and severe drought treatments $\left(F_{2,90}=4.57 ; P=0.01\right)$ were analyzed at each time of measurement. Mean net photosynthesis of control plants was greater than that of flood plants on 13 July $\left(t_{135}=-8.65 ; P<0.0001\right), 6$ Aug. $\left(t_{135}=-\right.$ $3.84 ; P=0.0006)$, and 30 Aug. $\left(t_{135}=-2.64\right.$; $P=0.0279$ ) (Table 1). Since these three comparisons of simple effects were all significant and in the same direction, their main effects were compared. Across all three dates, the mean net photosynthetic rate of flooded plants was $5.53 \mu \mathrm{mol} \cdot \mathrm{m}^{-2} \cdot \mathrm{s}^{-1}(95 \%$ CI: 4.20 to 6.86$)$ lower than that from the control plants $\left(t_{45}=-8.40 ; P<0.0001\right)$. Net photosynthetic rate of plants in the control treatment was greater than of those in the severe drought treatment on 13 July $\left(t_{135}=\right.$ 7.89; $P<0.0001), 6$ Aug. $\left(t_{135}=3.86 ; P=\right.$ $0.0006)$, and 30 Aug. $\left(t_{135}=4.88 ; P<0.0001\right)$ (Table 1). Averaging across time, the mean net photosynthetic rate of control plants was $6.08 \mu \mathrm{mol} \cdot \mathrm{m}^{-2} \cdot \mathrm{s}^{-1}(95 \% \mathrm{CI}: 4.76$ to 7.74$)$ higher than those in the severe drought treatment. Root zone water content of the medium ranged from $9.51 \%$ (severe drought treatment) to $76.5 \%$ (flood treatment) (Table 
Table 1. Mean photosynthetic rate, root zone moisture content, leaf area, and plant dry weight of potted Calycanthus occidentalis Hook. \& Arn. assigned to five soil-water treatments that were based on irrigation frequency. ${ }^{z}$

\begin{tabular}{|c|c|c|c|c|c|c|c|}
\hline \multirow[b]{2}{*}{ Treatment and time } & \multirow{2}{*}{$\begin{array}{l}\text { Photosynthetic rate } \\
\qquad\left(\mu \mathrm{mol} \cdot \mathrm{m}^{-2} \cdot \mathrm{s}^{-1}\right)\end{array}$} & \multirow{2}{*}{$\begin{array}{l}\text { Root zone } \\
\text { moisture content }(\%)\end{array}$} & \multirow{2}{*}{$\begin{array}{l}\text { Leaf area } \\
\left(\mathrm{cm}^{2}\right)\end{array}$} & \multicolumn{4}{|c|}{ Dry wt (g) } \\
\hline & & & & Leaf & Root & Stem & Total \\
\hline \multicolumn{8}{|l|}{ Across time } \\
\hline Control (moist) & 7.77 & 30.3 & 3092.4 & 18.7 & 96.6 & 29.4 & 145 \\
\hline Drought & $4.37^{* * *}$ & 21.2 & $2149.5 * * *$ & $9.89 *$ & $55.4 * * *$ & $22.1 *$ & $86.4^{* * *}$ \\
\hline Partial flood & $6.74 \mathrm{NS}$ & 66.3 & $3322.0 \mathrm{NS}$ & $19.7 \mathrm{NS}$ & $101 \mathrm{NS}$ & $27.8 \mathrm{NS}$ & 149 NS \\
\hline Flood & & & $395.45 * * *$ & $3.32 * * *$ & $12.3 * * *$ & $11.2 * * *$ & $26.8 * * *$ \\
\hline Severe drought & & & $1729.0 * * *$ & $13.9 \mathrm{NS}$ & $32.8 * * *$ & $20.4 * *$ & $67.1 * * *$ \\
\hline \multicolumn{8}{|l|}{ By time } \\
\hline \multicolumn{8}{|l|}{ Control (moist) } \\
\hline 13 July & 10.9 & 31.9 & & & & & \\
\hline 6 Aug. & 6.07 & 20.6 & & & & & \\
\hline 30 Aug. & 6.32 & 38.7 & & & & & \\
\hline \multicolumn{8}{|l|}{ Flood } \\
\hline 13 July & $1.44 * * *$ & 76.5 & & & & & \\
\hline 6 Aug. & $1.86^{* *}$ & 72.3 & & & & & \\
\hline 30 Aug. & $3.42 * *$ & 67.9 & & & & & \\
\hline \multicolumn{8}{|l|}{ Severe drought } \\
\hline 13 July & $2.28 * * *$ & 35.5 & & & & & \\
\hline 6 Aug. & $1.83 * *$ & 8.57 & & & & & \\
\hline 30 Aug. & $0.96^{* * *}$ & 9.51 & & & & & \\
\hline
\end{tabular}

${ }^{\mathrm{z}}$ Treatments began on 19 June 2006 and ended on 30 Aug. 2006. There were 50 plants of C. occidentalis and 10 replicates per treatment.

Ns, ${ }^{* * * * * * * *}$ Nonsignificant or significantly different from the control treatment mean within each column at $P \leq 0.05,0.001$, or 0.0001 , respectively.

1). Medium redox potential over time of C. occidentalis plants in the partial flood and flood treatments was on average -307 (95\% CI: -322 to -292$)$ and -292 (95\% CI: -302 to -282$) \mathrm{mV}$, respectively. Anaerobic conditions generally occur at soil redox potentials $200 \mathrm{mV}$ or less (Ponnamperuma, 1984).

No differences in leaf dry weight were found when comparing plants in the control treatment with those in the partial flood $(-0.98$ g, $95 \%$ CI: -6.48 to $4.52 ; P=0.99)$ and severe drought $(4.80 \mathrm{~g}, 95 \% \mathrm{CI}:-0.70$ to $10.30 ; P=0.25$ ) treatments, but leaf dry weight of the control plants was greater than that of plants in the drought $(8.81 \mathrm{~g}, 95 \% \mathrm{CI}$ : 3.16 to $14.5 ; P=0.01]$ and flood $(15.4 \mathrm{~g}$, $95 \%$ CI: 9.87 to $20.9 ; P<0.0001)$ treatments (Table 1). This overall pattern was consistent for leaf area and root, stem, and total dry weight data, except that control plants had greater leaf area $\left(1363.4 \mathrm{~cm}^{2}, 95 \%\right.$ CI: 988.12 to $1738.7 ; P<0.0001)$ and root $(63.8 \mathrm{~g}, 95 \%$ CI: 49.4 to $78.3 ; P<0.0001)$, stem $(8.99 \mathrm{~g}$,
95\% CI: 3.92 to $14.1 ; P=0.003)$, and total $(77.9 \mathrm{~g}, 95 \% \mathrm{CI}: 57.5$ to $97.8 ; P<0.0001)$ dry weight than those in the severe drought treatment (Table 1).

Fraxinus anomala. Mean net photosynthetic rates over time of $F$. anomala plants in the flooded and partially flooded treatments were, respectively, $10.0 \mu \mathrm{mol} \cdot \mathrm{m}^{-2} \cdot \mathrm{s}^{-1}(95 \%$ CI: 7.41 to $12.6 ; P<0.0001)$ and 7.49 $\mu \mathrm{mol} \cdot \mathrm{m}^{-2} \cdot \mathrm{s}^{-1}(95 \%$ CI: 4.89 to $10.1 ; P<$ $0.0001)$ less than that of plants in the control treatment (Table 2). No difference was found, however, between plants in the control and drought treatments $\left(-0.87 \mu \mathrm{mol} \cdot \mathrm{m}^{-2} \cdot \mathrm{s}^{-1}\right.$, 95\% CI: -3.31 to $1.57 ; P=0.4518$ ) (Table 2 ).

Simple effects of the severe drought versus control treatment were analyzed at each measurement period as a result of a significant interaction between these two treatments and time $\left(F_{2,24}=9.54 ; P=\right.$ $0.0009)$ (Table 2). Compared with the control treatment, the mean net photosynthetic rate of plants in the severe drought treatment was
$9.10 \mu \mathrm{mol} \cdot \mathrm{m}^{-2} \cdot \mathrm{s}^{-1}$ (95\% CI: 3.13 to $15.1 ; P=$ $0.0015)$ lower on 13 July, but not different $\left(-0.82 \mu \mathrm{mol} \cdot \mathrm{m}^{-2} \cdot \mathrm{s}^{-1}, 95 \% \mathrm{CI}:-6.79\right.$ to 5.15 ; $P=0.7312)$ on 6 Aug. or 30 Aug. $(-3.72$ $\mu \mathrm{mol} \cdot \mathrm{m}^{-2} \cdot \mathrm{s}^{-1}, 95 \% \mathrm{CI}:-8.84$ to $1.4 ; P=$ 0.0234) (Table 2). The water content of the root zones ranged from $29.4 \%$ (drought treatment) to $81.2 \%$ (partial flood treatment) (Table 2). Medium redox potentials over time of $F$. anomala plants in the partial flood and flood treatments were -280 (95\% CI: -313 to $-247)$ and -291 (95\% CI: -335 to -248$) \mathrm{mV}$, respectively.

Plants in the partial flood and flood treatments had less leaf, root, stem, and total dry weight than of those in the control treatment (Table 2). No differences in leaf, root, stem, and total dry weight were found between control plants and plants in the drought or severe drought treatments (Table 2). There was no evidence of differences in leaf area between control plants and those in the other treatments (Table 2).

Table 2. Mean photosynthetic rate, root zone moisture content, leaf area, and plant dry weight of potted Fraxinus anomala Torr. ex S. Watson assigned to five soil-water treatments that were based on irrigation frequency. ${ }^{z}$

\begin{tabular}{|c|c|c|c|c|c|c|c|}
\hline \multirow[b]{2}{*}{ Treatment and time } & \multirow{2}{*}{$\begin{array}{l}\text { Photosynthetic rate } \\
\left(\mu \mathrm{mol} \cdot \mathrm{m}^{-2} \cdot \mathrm{s}^{-1}\right)\end{array}$} & \multirow{2}{*}{$\begin{array}{l}\text { Root zone } \\
\text { moisture content }(\%)\end{array}$} & \multirow{2}{*}{$\begin{array}{l}\text { Leaf area } \\
\left(\mathrm{cm}^{2}\right)\end{array}$} & \multicolumn{4}{|c|}{ Dry wt $(\mathrm{g})$} \\
\hline & & & & Leaf & Root & Stem & Total \\
\hline Control (moist) & 11.2 & 44.8 & 1298.7 & 20.3 & 123 & 146 & 240.4 \\
\hline Flood & $0.22 * * *$ & 77.6 & $0.0000 \mathrm{NS}$ & $0.00^{*}$ & $0.00^{* *}$ & $0.00 * *$ & $0.00^{*}$ \\
\hline Severe drought & & & $1605.7 \mathrm{NS}$ & $14.6 \mathrm{NS}$ & $90.5 \mathrm{NS}$ & $125 \mathrm{NS}$ & $167 \mathrm{NS}$ \\
\hline \multicolumn{8}{|l|}{ By time } \\
\hline 6 Aug. & 11.6 & 44.1 & & & & & \\
\hline 30 Aug. & 8.68 & 43.7 & & & & & \\
\hline \multicolumn{8}{|l|}{ Severe drought } \\
\hline 13 July & $4.34^{* *}$ & 35.5 & & & & & \\
\hline 6 Aug. & $10.8 \mathrm{NS}$ & 34.8 & & & & & \\
\hline 30 Aug. & $12.4 \mathrm{NS}$ & 31.0 & & & & & \\
\hline
\end{tabular}

${ }^{\mathrm{z}}$ Treatments started on 19 June 2006 and ended on 30 Aug. 2006. There were 17 plants of $F$. anomala and four replicates per each drought treatment and three replicates per the other treatments.

${ }_{\mathrm{Ns}, * * * *, * * *}$ Nonsignificant or significantly different from the control treatment mean within each column at $P \leq 0.05,0.001$, or 0.0001 , respectively. 
Pinckneya pubens. There were no observed differences in mean net photosynthesis over time between $P$. pubens plants in the control and drought treatments (1.41 $\mu \mathrm{mol} \cdot \mathrm{m}^{-2} \cdot \mathrm{s}^{-1}, 95 \% \mathrm{CI}:-1.18$ to $4.00 ; P=$ 0.27 ) (Table 3). There were also no differences in mean net photosynthesis between plants in the control and partially flooded treatments $\left(-0.31 \mu \mathrm{mol} \cdot \mathrm{m}^{-2} \cdot \mathrm{s}^{-1}, 95 \% \mathrm{CI}\right.$ : -2.90 to $2.28 ; P=0.81)$ or between control plants and flood plants $\left(2.38 \mu \mathrm{mol} \cdot \mathrm{m}^{-2} \cdot \mathrm{s}^{-1}\right.$, 95\% CI: -0.20 to $4.98 ; P=0.07$ ) (Table 3 ).

As a result of an interaction between the control and severe drought treatments and time $\left(F_{2,50}=3.45, P=0.04\right)$, comparisons of the severe drought treatment to control were made at each drought cycle. There was statistical evidence of the control having greater net photosynthetic rates than the severe drought treatment at each time point. Hence, averaging across time, plants in the control treatment had a mean net photosynthetic rate that was $6.33 \mu \mathrm{mol} \cdot \mathrm{m}^{-2} \cdot \mathrm{s}^{-1}(95 \%$ CI: 3.74 to 8.92 ) higher than the severe drought plants (Table 3). Root zone water content of the medium spanned from $18.3 \%$ (severe drought treatment) to $78.6 \%$ (flood treatment) (Table 3). Medium redox potentials of $P$. pubens plants in the partial flood and flood treatments were $-110(95 \% \mathrm{CI}$ : -211 to -9.64$)$ and -200 (95\% CI: -263 to $-136) \mathrm{mV}$, respectively.

Although the stem dry weight of control plants was $6.60 \mathrm{~g}(95 \% \mathrm{CI}$ : 0.65 to $12.55 ; P=$ 0.03 ) greater than that of plants in the severe drought treatment, there were no mean differences in leaf, root, or stem dry weight between plants in the control treatment and the other treatments (Table 3). There were also no differences in mean leaf area between plants in the control treatment and the other treatments (Table 3 ).

\section{Discussion}

Calycanthus occidentalis and F. anomala tolerate soil moisture extremes that are similar to edaphic conditions in their native habitats. Calycanthus occidentalis, which is often found near stream banks or in moist canyons (Hickman, 1993), appears to not be suitable for cultivation in areas with greater than $\approx 66 \%$ and lower than $\approx 30 \%$ soil moisture content (Table 1). Similarly, the tolerance of $F$. anomala to moderately and severely dry, but not overly moist, soil moisture conditions was expected based on the arid nature of its natural range (Welsh, 1987). In contrast, the capacity of $P$. pubens to tolerate water stress, particularly dry soil conditions, is greater than its ecology would imply (Delprete, 1996) (Table 3). We conclude that although $P$. pubens and $F$. anomala are adapted to a relatively wide range of soil-water conditions, as demonstrated by their capacity to fix and allocate carbon near optimal levels while exposed to subor supraoptimal soil moisture conditions (Tables 2 and 3), C. occidentalis appears to only grow well under sufficiently moist soil conditions with adequate drainage (Hickman, 1993). In addition, our data demonstrated that growth and photosynthesis are effective indicators of the performance of ornamental woody species, at least under greenhouse conditions (Tables 1,2 , and 3 ).

The $F$. anomala plants we evaluated were collected from the most northern area of its distributional range (Albee et al., 1988; Welsh, 1987). Based on the climate and ecology of northeastern Utah and observations of plants cultivated in Iowa and Illinois (J. R. Stewart, unpublished data), it is likely that conspecific plants from this source can tolerate harsher environmental conditions than assumed. However, other abiotic and biotic factors, including the emerald ash borer (Agrilus planipennis Fairmaire) that feeds on several Fraxinus species in the midwestern United States (McCullough and Roberts, 2002), need to be taken into consideration before widespread cultivation.

While a specific provenance of $F$. anomala was identified for potential horticultural use due to its putative tolerance of extreme soil-moisture conditions, no similar efforts were made to select $P$. pubens and $C$. occi- dentalis plants from specific provenances. Based on research on other potentially stressresistant ornamental woody species (Balok and St. Hilaire, 2002; Bsoul et al., 2006), it is possible that some provenances of $C$. occidentalis exist that are located in relatively dry edaphic conditions. Further selection efforts could be made to identify droughttolerant selections of this highly attractive species. Although $P$. pubens holds promise as a species that should be evaluated further in field trials, future work should also focus on identifying superior selections that are even more tolerant of limited soil--water conditions than our results demonstrate. Indeed, although severe drought plants photosynthesized at lower levels than control plants, there were no differences in carbon-allocation patterns between plants in the two treatments (Table 3 ). Although the high variation in allocation patterns may account for this finding, it is possible that $P$. pubens exhibits some form of physiological adjustment that increases its resource-use efficiency under dry conditions (Stewart and Graves, 2004).

Pinckneya pubens is relatively easy to propagate vegetatively (Dirr, 1998) and may do well under exposed or shaded conditions. Moreover, the native habitat of $P$. pubens appears to be shrinking and any effort to cultivate it could be considered a form of conservation (J. Sharma, personal communication). Pinckneya pubens is a promising horticultural species that should be evaluated further in the field to determine its ability to survive in a wider range of conditions.

Although the species were not compared statistically, it is interesting to note that the medium redox potentials of flooded and partially flooded $P$. pubens plants were substantially lower than the medium redox potentials of similarly treated plants of the other two species. Pinckneya pubens appears to have some physiochemical means of adjusting its rhizophere to anaerobic conditions. Other species have been found to adjust to low oxygen conditions by developing aerenchyma, adventitious roots, or expanded lenticels to improve gas exchange in roots

Table 3. Mean photosynthetic rate, root zone moisture content, leaf area, and plant dry weight of potted Pinckneya pubens Michx. assigned to five soil-water treatments that were based on irrigation frequency. ${ }^{z}$

\begin{tabular}{|c|c|c|c|c|c|c|c|}
\hline \multirow[b]{2}{*}{ Treatment and time } & \multirow{2}{*}{$\begin{array}{l}\text { Photosynthetic rate } \\
\quad\left(\mu \mathrm{mol} \cdot \mathrm{m}^{-2} \cdot \mathrm{s}^{-1}\right)\end{array}$} & \multirow{2}{*}{$\begin{array}{c}\text { Root zone } \\
\text { moisture content }(\%)\end{array}$} & \multirow{2}{*}{$\begin{array}{l}\text { Leaf area } \\
\left(\mathrm{cm}^{2}\right)\end{array}$} & \multicolumn{4}{|c|}{ Dry wt (g) } \\
\hline & & & & Leaf & Root & Stem & Total \\
\hline \multicolumn{8}{|l|}{ Across time } \\
\hline Control (moist) & 8.80 & 38.6 & 1639.7 & 23.5 & 18.2 & 16.4 & 58.1 \\
\hline Drought & $7.39 \mathrm{NS}$ & 22.1 & 1095.4 NS & $12.1 \mathrm{NS}$ & $16.2 \mathrm{NS}$ & $14.7 \mathrm{NS}$ & $41.0 \mathrm{NS}$ \\
\hline Partial flood & $9.11 \mathrm{NS}$ & 72.7 & $1733.8 \mathrm{NS}$ & $53.9 \mathrm{NS}$ & $15.7 \mathrm{NS}$ & $16.7 \mathrm{NS}$ & $86.3 \mathrm{NS}$ \\
\hline Flood & $6.41 \mathrm{NS}$ & 78.6 & $1335.1 \mathrm{NS}$ & $20.4 \mathrm{NS}$ & $16.8 \mathrm{NS}$ & $16.9 \mathrm{NS}$ & $54.0 \mathrm{NS}$ \\
\hline Severe drought & & & $660.55 \mathrm{NS}$ & $11.3 \mathrm{NS}$ & $7.88 \mathrm{NS}$ & $9.82 *$ & $29.0 \mathrm{NS}$ \\
\hline \multicolumn{8}{|l|}{ By time } \\
\hline \multicolumn{8}{|l|}{ Control (moist) } \\
\hline 13 July & 11.7 & 41.0 & & & & & \\
\hline 6 Aug. & 6.72 & 27.0 & & & & & \\
\hline 30 Aug. & 7.97 & 47.8 & & & & & \\
\hline \multicolumn{8}{|l|}{ Severe drought } \\
\hline 13 July & $3.26 * * *$ & 31.6 & & & & & \\
\hline 6 Aug. & $2.62 * *$ & 23.1 & & & & & \\
\hline 30 Aug. & $1.54 * *$ & 18.3 & & & & & \\
\hline
\end{tabular}

zTreatments were initiated on 19 June 2006 and ended on 30 Aug. 2006. There were 30 plants of $P$. pubens and six replicates per treatment.

Ns, ${ }^{*}, * *, * * * *$ Nonsignificant or significantly different from the control treatment mean within each column at $P \leq 0.05,0.001$, or 0.0001 , respectively. 
(Crawford and Braendle, 1996; Ojeda et al., 2004; Schaffer et al., 1992). More research needs to be done to understand the means by which this intriguing species is able to tolerate flooded conditions as well as dry conditions. In addition, it leads to a more fundamental question as to why certain woody species from moist habitats are adaptable to soil moisture extremes [e.g., Fraxinus pennsylvanica Marshall (Whitlow et al., 1992) and Taxodium distichum (L.) Rich. (Nash and Graves, 1993)], but others are not [e.g., Cornus florida L. (Croker et al., 1998) and Acer pensylvanicum L. (Pijut, 2005)]. Pinckneya pubens and C. occidentalis both naturally occur in moist habitats, but $P$. pubens is substantially more adapted to drought and flooding events. The underlying mechanisms that enable some bottomland woody species to be drought-tolerant need to be explored further to help in making future selections of stress-tolerant species and cultivars.

Measuring the carbon fixation and allocation patterns of these species under a gradation of soil moisture levels provides a cursory estimate of their potential performance in the field. Widespread cultivation of each species may not be possible as a result of limitations related to cold hardiness, but further work is needed to determine if the cold hardiness of each taxa is greater than that required by the climate of their natural range as has been shown for other woody species (Flint, 1972; Parker, 1963; Schrader and Graves, 2003).

The involvement of horticulture in the introduction of invasive plant species has been recognized (Mack, 2005; Reichard and White, 2001) and provides incentive to evaluate the invasive potential of each of these species. Although the factors contributing to the invasiveness are numerous and complex (Lockwood et al., 2007; Lonsdale and Smith, 2001), there are a few traits that are hallmark characteristics of invaders that should be investigated. These include time to reproduction (Rejmánek and Richardson, 1996), fecundity (Stewart and Graves, 2006), flowering period (Mack, 2005), and seed germinability (Baker, 1974; Perrins et al., 1992).

\section{Literature Cited}

Albee, B.J., L.M. Schultz, and S. Goodrich. 1988. Atlas of the vascular plants of Utah. Utah Museum of Natural History, Salt Lake City, UT.

Baker, H.G. 1974. The evolution of weeds. Annu. Rev. Ecol. Syst. 5:1-24.

Balok, C.A. and R. St. Hilaire. 2002. Drought responses among seven southwestern land- scape tree taxa. J. Amer. Soc. Hort. Sci. 127:211-218

Bsoul, E., R. St. Hilaire, and D.M. VanLeeuwen. 2006. Bigtooth maples exposed to asynchronous cyclic irrigation show provenance differences in drought adaptation mechanisms. J Amer. Soc. Hort. Sci. 131:459-468.

Campbell, G.E., R.J. Brazee, A.E. Endress, T.B Voigt, D.F. Warnock, and J.L. Hall. 2001. The Illinois green industry: Economic impact, structure, characteristics. University of Illinois at Urbana-Champaign.

Crawford, R.M.M. and R. Braendle. 1996. Oxygen deprivation stress in a changing environment. J. Expt. Bot. 47:145-159.

Croker, J., W. Witte, and R. Auge. 1998. Stomatal sensitivity of six temperate, deciduous tree species to non-hydraulic root-to-shoot signalling of partial soil drying. J. Expt. Bot. 49:761774 .

Delprete, P.G. 1996. Systematics, typification, distribution, and reproductive biology of Pinckneya bracteata (Rubiaceae). Plant Syst. Evol. 201:243-261.

Dirr, M.A. 1998. Manual of woody landscape plants: Their identification, ornamental characteristics, culture, propagation, and uses. Stipes Publ., Champaign, IL.

Dougherty, P.M., R.O. Teskey, J.E. Phelps, and T.M. Hinckley. 1979. Net photosynthesis and early growth trends of a dominant white oak (Quercus alba L.). Plant Physiol. 64:930-935.

Flint, H.L. 1972. Cold hardiness of twigs of Quercus rubra L. as a function of geographic origin. Ecology 53:1163-1170.

Grant, V. 1950. The pollination of Calycanthus occidentalis. Amer. J. Bot. 37:294-297.

Harris, R.W., J.R. Clark, and N.P. Matheny. 1999. Arboriculture: Integrated management of landscape trees, shrubs, and vines. Prentice-Hall, Upper Saddle River, NJ.

Hickman, J.C. 1993. The Jepson manual: Higher plants of California. University of California Press, Berkeley.

Kjelgren, R., L. Rupp, and D. Kilgren. 2000. Water conservation in urban landscapes. HortScience 35:1037-1040.

Landhäusser, S.M. and V.J. Lieffers. 2001. Photosynthesis and carbon allocation of six boreal tree species grown in understory and open conditions. Tree Physiol. 21:243-250.

Lockwood, J.L., M.F. Hoopes, and M.P. Marchetti. 2007. Invasion ecology. Blackwell Publ., Oxford, UK

Lonsdale, W.M. and C.S. Smith. 2001. Evaluating pest-screening systems: Insights from epidemiology and ecology, p. 52-60. In: Groves, R.H., F.D. Panetta, and J.G. Virtue (eds.). Weed risk assessment. CSIRO, Collingwood, Australia.

Mack, R.N. 2005. Predicting the identity of plant invaders: Future contributions from horticulture. HortScience 40:1168-1174.

McCarron, J.K. and A.K. Knapp. 2001. $C_{3}$ woody plant expansion in $\mathrm{C}_{4}$ grassland: Are grasses and shrubs functionally distinct? Amer. J. Bot. 88:1818-1823.
McCullough, D.G. and D.L. Roberts. 2002. Pest alert: Emerald ash borer. United States Forest Service, Northeastern Area.

Nash, L.J. and W.R. Graves. 1993. Drought and flood stress effects on plant development and leaf water relations of 5 taxa of trees native to bottomland habitats. J. Amer. Soc. Hort. Sci. 118:845-850

Ojeda, M., B. Schaffer, and F.S. Davies. 2004. Flooding, root temperature, physiology and growth of two Annona species. Tree Physiol. 24:1019-1025.

Parker, J. 1963. Cold resistance in woody plants. Bot. Rev. 29:123-201.

Perrins, J., M. Williamson, and A. Fitter. 1992. Do annual weeds have predictable characters? Acta Oecologica 13:517-533.

Pijut, P.M. 2005. Planting and care of fine hardwood seedlings. Purdue University, West Lafayette, IN.

Ponnamperuma, F. 1984. Effect of flooding on soils, p. 9-42. In: Kozlowski, T.T. (ed.). Flooding and plant growth. Academic Press, London.

Reichard, S.H. and P. White. 2001. Horticulture as a pathway of invasive plant introductions in the United States. Bioscience 51:103-113.

Rejmánek, M. and D.M. Richardson. 1996. What attributes make some plant species more invasive? Ecology 77:1655-1661.

Schaffer, B., P.C. Andersen, and R.C. Ploetz. 1992. Responses of fruit crops to flooding, p. 257313. In: Janick, J. (ed.). Horticultural reviews. Vol. 13. Wiley, New York.

Schrader, J.A., S.J. Gardner, and W.R. Graves. 2005. Resistance to water stress of Alnus maritima: Intraspecific variation and comparisons to other alders. Environ. Exp. Bot. 53:281-298.

Schrader, J.A. and W.R. Graves. 2003. Phenology and depth of cold acclimation in the three subspecies of Alnus maritima. J. Amer. Soc. Hort. Sci. 128:330-336.

Shevock, J.R., B. Ertter, and D.W. Taylor. 1992 Neviusia cliftonii (Rosaceae: Kerrieae), an intriguing new relict species from California. Novon 2:285-289.

Stewart, J.R. and W.R. Graves. 2004. Photosynthesis and growth of Rhamnus caroliniana during drought and flooding: Comparison to the invasive Rhamnus cathartica. HortScience 39:1278-1282.

Stewart, J.R. and W.R. Graves. 2006. Photosynthesis, growth, carbon allocation, and fruit load of Frangula caroliniana and Rhamnus cathartica. Int. J. Plant Sci. 167:11611168

Welsh, S. 1987. A Utah flora. Brigham Young University Press, Provo, UT.

Westfall, P.H., R.D. Tobias, D. Rom, R.D. Wolfinger, and Y. Hochberg. 1999. Multiple comparisons and multiple tests using the SAS system. SAS Inst., Cary, NC.

Whitlow, T.H., N.L. Bassuk, and D.L. Reichert. 1992. A 3-year study of water relations of urban street trees. J. Appl. Ecol. 29:436-450. 